\title{
QUETIAPINE POISONING ASSOCIATED WITH NEUROLEPTIC MALIGNANT SYNDROME, RHABDOMYOLYSIS AND RENAL FAILURE: A CASE REPORT
}

\author{
Željko Ninčević ${ }^{1}$, Davor Lasić ${ }^{2}$, Trpimir Glavina ${ }^{2}$, Marijana Mikačić ${ }^{3}$, \\ Mladen Carev ${ }^{1} \&$ Kristian Podrug ${ }^{3}$ \\ ${ }^{I}$ Department of Anaesthesiology and Intensive Care Medicine, University Hospital Centre Split, Split, Croatia \\ ${ }^{2}$ Department of Psychiatry, University Hospital Centre Split, Split, Croatia \\ ${ }^{3}$ Department of Internal Intensive Care Medicine, University Hospital Centre Split, Split, Croatia
}

received: 26.11.2016;

revised: 5.12.2016;

accepted: 1.2.2017

$* * * * *$

\section{INTRODUCTION}

Quetiapine extended release (XR) has been used to treat various psychiatric disorders, including psychotic disorders, acute mania and depressive episodes associated with bipolar I and II disorders. Quetiapine XR is generally safe and well tolerated. There are few reports of deaths or significant permanent morbidity associated with quetiapine overdose.

We present a case of I.E.K., a 32-year-old male patient, who was admitted to Intensive care unit University Hospital Centre in Split, Croatia, for intoxication with an extreme overdose of quetiapine (24 g), ingested to attempt suicide. The emergency medical service found the patient comatose with response only to deep painful stimuli and Glasgow Coma Score (GCS) of a 6. He was discovered 15 hours after ingestion of $24 \mathrm{~g}$ quetiapine (60 tablets of $400 \mathrm{mg} \mathrm{XR}$ ) and $5 \mathrm{mg}$ of alprazolam (10 tablets of $0.5 \mathrm{mg}$ ) after consuming alcohol through the night. He developed neuroleptic malignant syndrome with rhabdomyolysis and renal failure. After appropriate treatment the patient recovered completely.

\section{CASE REPORT}

A 32-year-old male had experienced the first episode of depressed mood in borderline personality disorder eight months before and the episode we report was his second exacerbation. Because of the marital problems, after consuming alcohol he ingested $24 \mathrm{~g}$ of quetiapine (60 tablets of $400 \mathrm{mg} \mathrm{XR}$ ) and $5 \mathrm{mg}$ of alprazolam (10 tablets of $0.5 \mathrm{mg}$ ) to attempt suicide. The emergency medical service found the patient 15 hours after ingestion comatose with response only to deep painful stimuli and GCS of a 6. During the transport to the hospital 40 $\mathrm{mg}$ of furosemide and $1000 \mathrm{~mL}$ saline were administered for detoxification and prophylaxis of hypotension. He had no history of severe somatic disorder, he was non-smoker and he consumed alcohol occasionally. There was no evidence of trauma or infection.
The skin was warm and moist. The pupils were $3 \mathrm{~mm}$, equal, and minimally reactive to light. The abdomen was soft and not distended.

On admission to the Intensive care unit he was hypotensive (96/47 mmHg), with sinus tachycardia of 133 beats per minute and respiratory rate of 25/min. Arterial blood oxygen saturation was 75\%. Initial ECG showed slight prolongation of the QRS complex (110 miliseconds). On a chest X-ray inhomogeneous shading of lung parenchyma on both sides was visible.

Immediately upon admittance orotracheal intubation and mechanical ventilation started. Gastric lavage was performed through a nasogastric tube and no pill fragments of ingested tablets were found. He received 60 $\mathrm{mg}$ of activated charcoal. Two vials of flumazenil (0.2 mg each) were administered intravenously but the level of consciousness did not improve. The patient became febrile, his axillary temperature measured up to $38.7^{\circ} \mathrm{C}$, with profuse sweating. The patient was diagnosed with neuroleptic malignant syndrome based on his clinical presentation and laboratory values. Rhabdomyolysis developed with very high values of creatinephosphokinase (120 $000 \mathrm{U} / \mathrm{L}$ on the $\left.2^{\text {nd }} d a y\right)$, creatinine (518 $\mu \mathrm{mol} / \mathrm{L}$ on the $2^{\text {nd }}$ day) and C-reactive protein (318.8 $\mathrm{mg} / \mathrm{L}$ on the $2^{\text {nd }}$ day), and he became anuric. Both arms and both legs were of high muscle tone and he had a muscular jerks of the whole body. Ultrasound examination of the skeletal muscle of the lower limb showed diffuse edema especially of the lower leg. The muscles of the lower leg were of deteriorated ultrasound structure in terms of rhabdomyolysis (Figure 1).

Central venous catheter and arterial line were inserted for invasive hemodynamic monitoring. Dantrolene $2.5 \mathrm{mg} / \mathrm{kg}$ i.v. was administered. Normal saline, fresh frozen plasma, antibiotics (ceftriaxone, moxifloxacine), gastric protection (pantoprazole) and continuous infusion of morphine and midazolam were administered as well as intravenous infusion of norepinephrine. During the same day continuous veno-venous hemodiafiltration (CVVHDF) started. He was on a ventilator six days. When control chest X-rays showed regression of the infiltration of the lung parenchyma continuous sedation 
was stopped and he was successfully weaned from the ventilator and extubated. On the day of extubation the contact with the patient has been established, he followed orders, become oriented and aware what he has done. CVVHDF was performed eight days and intermittent hemodialysis was carried out for the next nine days, two hours each day. Gradually there was a regression of elevated laboratory results (Table 1). After weaning from the ventilator right-sided paresis of peroneal nerve that required treatment of physiatrist was observed. Symptoms of neuroleptic malignant syndrome resolved in a week.

After somatic recovery he was transferred to our acute psychiatric ward. Reintroducing antipsychotic treatment has been in line with the treatment algorithm for a major depressive disorder and borderline personality disorder, including clinical presentation by illness stage or severity. We started quetiapine from relatively low doses (25 mg/day) with slow titration up to 400 $\mathrm{mg} /$ day over 10 days. The patient remained in the hospital for a 29 days after intoxication with extreme oral overdose of quetiapine to attempt suicide and was discharged without sequelae.

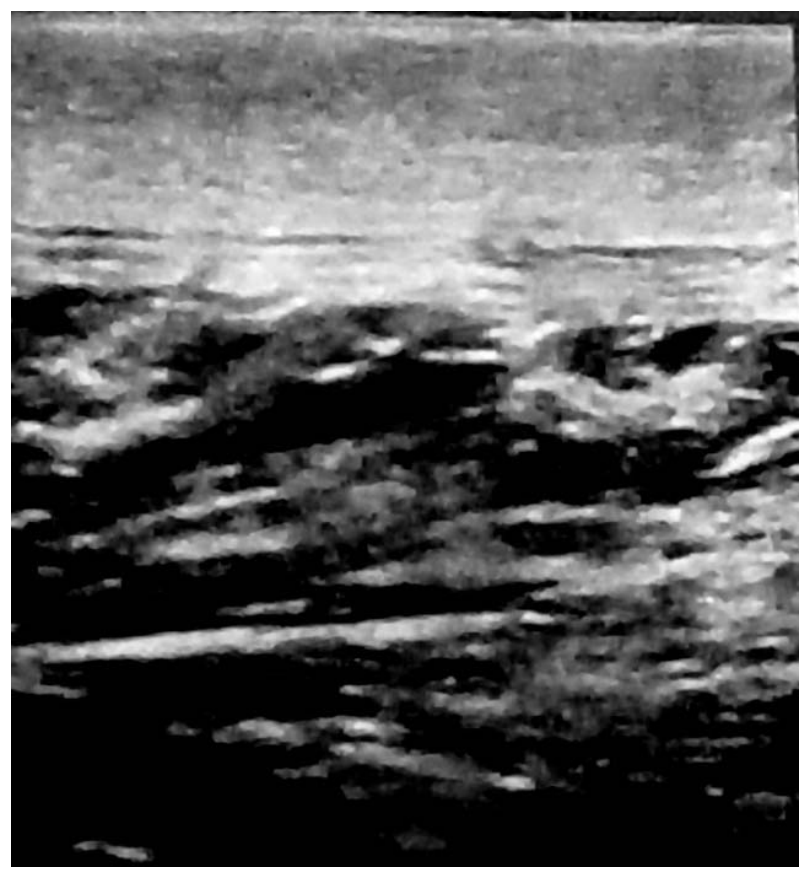

Figure 1. Disturbed ultrasound structure of popliteal muscles affected by rhabdomyolysis

Table 1. Laboratory findings before CVVHDF ( $\left.1^{\text {st }} d a y\right)$ and after CVVHDF has started $\left(2^{\text {nd }}\right.$ day)

\begin{tabular}{lccccccc}
\hline \multicolumn{1}{c}{ Day } & 1 & 2 & 3 & 4 & 5 & 9 & 10 \\
\hline Pletelets $(x 10 / \mathrm{L})$ & 216 & 191 & 125 & 117 & 127 & 135 & 170 \\
Urea $(\mathrm{mmol} / \mathrm{L})$ & 9 & 14.9 & 17.9 & 16.7 & 17.9 & 21.3 & 22.2 \\
Creatinine $(\mu \mathrm{mol} / \mathrm{L})$ & 191 & 518 & 471 & 433 & 415 & 386 & 400 \\
Creatinine phosphokinase (U/L) & 92000 & 120846 & 58622 & 33913 & 17829 & 2470 & 2353 \\
Myoglobin $(\mu \mathrm{g} / \mathrm{L})$ & & & 41142 & & & 9829 & \\
Potassium $(\mathrm{mmol} / \mathrm{L})$ & 4.3 & 5.5 & 3.9 & 4.6 & 3.7 & 4.4 & 3.2 \\
Total bilirubin $(\mu \mathrm{mol} / \mathrm{L})$ & 12 & 10.2 & 8.8 & 8.2 & 7.8 & 9.6 & 7.6 \\
AST (U/L) & 36 & 2222 & 886 & 720 & 538 & 200 & 152 \\
ALT (U/L) & 22 & 598 & 366 & 340 & 325 & 245 & 228 \\
GGT (U/L) & 44 & 34 & 23 & 76 & 80 & 191 & 192 \\
CRP (mg/L) & & 318.8 & 306 & & 205.3 & & \\
\hline
\end{tabular}

\section{DISCUSSION}

Quetiapine is an atypical antipsychotic that has been used to treat various psychiatric disorders in adults, including psychotic disorders, acute mania and depressive episodes associated with bipolar I and II disorders (DeVane\& Nemeroff 2001). Quetiapine is an antagonist at multiple neurotransmitter receptors in the brain (serotonin 5-HT1A and 5-HT2, dopamine D1 and D2, histamine $\mathrm{H} 1$, and adrenergic alpha1 and alpha2 receptors). In comparison to other antipsychotic agents, quetiapine has less antimuscarinic and alpha1 antagonist receptor activity. The antipsychotic effect is explained by the antagonistic effect on D2 receptors and and 5-HT 2A receptors (Dev 2000). Adverse effects like sedation and somnolence are explained by antagonism of histamin H1 receptors. Ortostatic dysregulation, hypotension, and tacycardia are associated with an antagonistic effect on $\alpha 1$-adrenergic receptors. Quetiapine has also been reported to have an antagonistic effect on M1-muscarinic receptors resulting in anticholinergic mediated tacyhcardia (DeVane \& Nemeroff 2001). Several reports have revealed the relative safety of quetiapine in overdose up to 20000 mg. The first such case report was an intoxication with an extreme dose of quetiapine (36000 mg), ingested by 32-year-old female (62 kg bodyweight) to attempt suicide. Symptoms associated with intoxication were coma without arterial hypotension, persistent tachycardia, hyperglycaemia and transient hypothryoidism. QTc-interval was moderately extended. Management consisted of intubation for airway protection, gastric lavage, the use of activated charcoal, i.v. saline and observation. The patient recovered completely without residual symptoms (Muller et al. 2009). 
The first fatal case has been published by Fernandes \& Marcil (2002), factors possibly contributing to the death of the 52-year-old patient were a history of cardiac dysrythmia and hypertensive heart desease. Ngo et al. (2008) in a 5-year retrospective case series found 945 cases of acute quetiapine overdose in adults, among them 3 deaths, all of whom had coma, tachycardia, and respiratory depression requiring ventilatory support.

Consequences of acute quetiapine overdose included coma, respiratory depression, and hypotension, but in our case the patient experienced neuroleptic malignant syndrome, rhabdomyolysis and acute renal failure (Smith et al. 2004).

Neuroleptic malignant syndrome is a rare, but lifethreatening, idiosyncratic reaction characterized by fever, muscular rigidity, altered mental status, and autonomic dysfunction. The syndrome was first described by Delay and colleagues in 1960, in patients treated with high-potency antipsychotics. The mortality rate rises to about $50 \%$ if neuroleptic malignant syndrome is complicated by renal failure. Once the syndrome starts, it usually evolves over 24-72 hours (Chiou et al 2015). Treated with dantrolen, while taking care of comorbid symtpoms in Intensive care unit, in our case as in literature, simptoms of neuroleptic malignant syndrome resolved within a week.

Each psychopharmac, regardless of its administration safety and the positive clinical experiences, can pose a potential risk of side effects. The treatment of overdose with quetiapine is mainly supportive, as there is no specific antidote to quetiapine. According to Burns (2001) risk of death after poisoning with quetiapine is low, but large overdose may cause serious clinical features such as loss of consciousness, respiratory depression, hypotension, tachycardia, arrythmia, seizures, neuroleptic malignant syndrome, rhabdomyolysis and acute renal failure. Despite quetiapine's safety record in overdose, medical comorbidity in extreme overdoses may contribute to a fatal outcome. All patients with acute quetiapine overdose who require hospitalization should be monitored in an intensive care unit setting.

\section{CONCLUSION}

We described a case with complicated clinical presentation, but recovered without any consequences. Unique characteristics in this case included symptoms of developed Neuroleptic malignant syndrome with rhabdomyolysis and acute renal failure as a consequences of intoxication after extreme overdose of quetiapine to attempt suicide. Still, quetiapine extended release (XR) is a safe atypical antipsychotic. Our patient recovered completely without residual symptoms, but we must always keep in mind that overdose with quetiapine may be associated with coma, respiratory depression, hypotension, QT prolongation, neuroleptic malignant syndrome, extreme rhabdomyolysis and acute renal failure. Major overdoses of quetiapine warrant close observation in an intensive care setting.

\section{Acknowledgements: None.}

\section{Conflict of interest: None to declare.}

\section{Contribution of individual authors:}

Željko Ninčević was involved with the patient's care, data collection and manuscript preparation.

Davor Lasić was involved with conception and design, manuscript preparation and writing the paper.

Trpimir Glavina was involved with writing the paper.

Mladen Carev was involved in manuscript preparation, reviewed draft manuscript.

Marijana Mikačić was involved with the patient's care and manuscript preparation.

Kristian Podrug was involved with the patient's care and data collection.

\section{References}

1. Burns MJ. The pharmacology and toxicology of atypical antipsychotic agents. Journal of toxicology Clinical toxicology 2001; 39:1-14.

2. Chiou YJ, Lee Y, Lin CC, Huang TL. A Case Report of Catatonia and Neuroleptic Malignant Syndrome With Multiple Treatment Modalities: Short Communication and Literature Review. Medicine 2015; 94:1752.

3. DeVane CL, Nemeroff CB. Clinical pharmacokinetics of quetiapine: an atypical antipsychotic. Clinical pharmacokinetics. 2001; 40:509-22.

4. Dev V, Raniwalla J: Quetiapine: a review of its safety in the management of schizophrenia. Drug safety: an international journal of medical toxicology and drug experience. 2000; 23:295-307.

5. Fernandes PP, Marcil WA: Death associated with quetiapine overdose. The American journal of psychiatry. 2002;159:2114.

6. Muller $C$, Reuter H, Dohmen C: Intoxication after extreme oral overdose of quetiapine to attempt suicide: pharmacological concerns of side effects. Case reports in medicine. 2009;2009:371698.

7. Ngo A, Ciranni M, Olson KR: Acute quetiapine overdose in adults: a 5-year retrospective case series. Annals of emergency medicine. 2008; 52:541-7.

8. Smith RP, Puckett BN, Crawford J, Elliott RL: Quetiapine overdose and severe rhabdomyolysis. Journal of clinical psychopharmacology. 2004; 24:343.

\section{Correspondence:}

